\title{
INYI Global Network
}

Our INYI members span the following countries: BRAZIL, CANADA, GERMANY, ITALY, PORTUGAL, SOUTH KOREA, SWITZERLAND, and UNITED STATES OF AMERICA.

To SUBSCRIBE to the INYI Journal, and to join our mailing list, please email at inyi@yorku.ca with your full name, email address, your designation, your research interests, and where you learnt about INYI Journal. 


\section{INYI Journal}

Editor-in-Chief: Nazilla Khanlou

Managing Editor: Luz Maria Vazquez York University, 4700 Keele Street

Toronto, ON, Canada, M3J 1P3

E-mail: owhchair@yorku.ca

Website: http://nkhanlou.info.yorku.ca/ Follow us at: https://twitter.com/YorkUOWHC ISSN 1929-8471 